\title{
Trehalose, a new panacea?
}

\section{La trehalosa: ¿una nueva panacea?}

\author{
Lorena C. Torres-Acosta*, Stephanie M. García-Alarcón and Luisa E. Mayta-Pitman
}

Instituto Nacional de Oftalmología, Lima, Peru

Dear Editor:

We have shown interest in the article "Effect of 3\% topical trehalose on the rate of corneal re-epithelialization in patients undergoing photorefractive keratectomy"1, which we consider an interesting investigation because it is related to ocular surface alterations, a very frequent adverse event after refractive surgery, which generates great discomfort in patients and a vicious circle that is difficult to stop.

Trehalose acts as an enzyme with activity in proteoglycans involved in healing. After the administration of topical trehalose, there was an ability to protect protein structures and contribute to the organization and re-epithelialization of tissue, thanks to the ubiquitin-proteasome system and lysosomal autophagic clearance, which are activated to repair damaged proteins. Likewise, the literature reports an increase in the expression of $\mathrm{P} 62$, an autophagy receptor that increases the expression of antioxidants and reduces the amount of free radicals, thus preventing cell dam$\mathrm{age}^{2}$. The combination of sodium hyaluronate with trehalose in eye drops has shown great effectiveness in corneal re-epithelialization after interventions such as LASIK (laser-assisted in situ keratomileusis) and PRK (photorefractive keratectomy) compared to the use of hyaluronate alone, by reducing the number of dead cells on the ocular surface due to apoptosis supression ${ }^{3}$.

In the study by Haber, et al. ${ }^{1}$ it was shown that the corneal epithelialization rate did not increase after the administration of topical trehalose, unlike the work carried out by Aragona et al. ${ }^{4}$, who concluded that the use of said drug did contribute to corneal re-epithelialization. This is probably due to the fact that Aragona used more specific parameters to explain corneal re-epithelialization, such as morphometric analyses that determined the percentage of vital cells, the number of epithelial layers, epithelial thickness, the area of basal cells, the optical density of the cytoplasm and tomographic images, thus contributing to obtaining more consistent data.

Due to the aforementioned, we consider that the study by Haber, et al. ${ }^{1}$ may have verified his hypothesis; however, more specific tests are needed to explain the corneal re-epithelialization process in greater detail. 
Finally, considering the different realities in which these studies can be carried out, the commitment to continue searching for low-cost tests for the follow-up of corneal re-epithelialization remains pending.

\section{Conflicts of interest}

The authors declare no conflicts of interest.

\section{References}

1. Haber A., Polania-Barón EJ. Efecto de la trehalosa tópica al 3\% en la velocidad de epitelización corneal en pacientes operados de queratectomía fotorrefractiva. Rev Mex Oftalmol. 2021;95:71-5.

2. Luyckx J, Baudouin C. Trehalose: an intriguing disaccharide with potential for medical application in ophthalmology. Clin Ophthalmol. 2011; 5:577-81.

3. Laihia J, Kaarniranta K. Trehalose for ocular surface health. Biomolecules. 2020;10:809.

4. Aragona P, Colosi P, Rania L, Colosi F, Pisani A, Puzzolo D, et al. Protective effects of trehalose on the corneal epithelial cells. Sci World J. 2014;2014:717835. 